\title{
ANTI-RHEUMATIC ACTIVITY OF SEVERAL STEROIDS
}

\author{
BY \\ ROBERT LIEFMANN* \\ McGill University Clinic, Royal Victoria Hospital, Montreal, Canada
}

One of the problems in rheumatology research is the variation in reported results of the anti-rheumatic effects of new substances. This paper presents methods of eliminating the variables which are felt to be responsible for the diversity of views of investigators in this field, together with data on the relative anti-rheumatic activity of several steroids. The effect of ACTH and cortisone, pregnenolone, acetoxypregnenolone, testosterone, and other steroids has already been studied in rheumatoid arthritis, but a quantitative assay of their anti-rheumatic activity is needed. The more definite anti-rheumatic effect of cortisone and ACTH offers a good standard of comparison. Previous studies have indicated interesting metabolic effects of testosterone in rheumatoid arthritis, and a further study of the possible anti-rheumatic activity of testosterone was therefore undertaken.

It is apparent that the basis of the variation in the reported anti-rheumatic effects of new substances lies in certain uncontrolled variables, of which the following are the most significant in rheumatoid arthritis:

(1) psychic factors,

(2) spontaneous variation in disease activity,

(3) degree of activity of the disease,

(4) pre-existing endocrine imbalance.

(1) The importance of psychic factors has been much emphasized. Any experiment must involve methods of controlling this factor. Most important of these is the selection of patients whose disease has been followed for a long period and whose response to other forms of therapy (especially to placebo administration) under conditions identical with those of the experiment is known.

(2) In a disease with so great an incidence of spontaneous remission or improvement as rheumatoid arthritis (Short and Bauer, 1948), it is well to select patients who have had little variation for a long time, and to prefer a few, longterm studies to numerous, short-term observations.

(3) With present methods the severity of the disease can be estimated only from the signs and symptoms, elevation of sedimentation rate, rate of progression, and duration of disease.

(4) Should endocrine imbalance be involved in the pathogenesis of rheumatoid arthritis (Hench and others, 1949; Liefmann, 1950), the quantitative degree of imbalance of the one or more hormones involved varies in different patients.

\footnotetext{
* Supported by a grant from the Canadian Arthritis and Rheumatism Association.
} 
Thus the results of studies in rheumatoid arthritis differ widely according to the selection of patients. The anti-rheumatic effect of a substance to be tested may appear to be very marked in a mildly active, easily reversible case and may be undetectable in a severely active case.

\section{Assay of New and Untested Steroids in Terms of the Anti-Rheumatic Activity of Cortisone by the Method of Partial Substitution}

Theoretical Bases of Study.-In order to standardize the anti-rheumatic steroids, it is highly desirable that the mechanism of action of any anti-rheumatic compound be known. For example, Hench and others (1949) established that the most active anti-rheumatic steroids are the glucocorticoids (17-11-oxycorticosteroids).

However, the anti-rheumatic effects of compound $\mathrm{E}$ (cortisone) and compound $\mathrm{F}$ have not been shown to be mediated through their action on carbohydrate metabolism or even to be proportional to this activity. If this were so, a simple means of assaying and developing new anti-rheumatic steroids might be readily available. To avoid the necessity of making any unfounded assumption regarding the mechanism of action of the steroids to be tested for anti-rheumatic activity, an empirical method of comparing unknown steroids with cortisone as a standard has been developed. Let us suppose that with a standard dose of cortisone (e.g. $100 \mathrm{mg}$. $/ 24 \mathrm{hrs}$ ) a remission is obtained in a case of rheumatoid arthritis. An aliquot is then subtracted from the dose and an unknown steroid substituted for it.

For example, the dose of cortisone may be lowered to $25 \mathrm{mg} . / 24 \mathrm{hr}$ until exacerbation with minimal arthritis signs and symptoms recurs; the unknown steroid is then added in increasing amounts until remission again occurs (or negative results are obtained). The amount of " unknown" necessary to effect remission is then equated to the aliquot of cortisone replaced (in our example $75 \mathrm{mg}$.), and the anti-rheumatic activity of the unknown is related to that of cortisone, taking the latter as 100 per cent. For example, if $200 \mathrm{mg}$. of the unknown be required to cause remission, then $\frac{75}{200} \times 100=x$ per cent.

An assumption is inherent in this method, namely that the unknown and cortisone both have the same mechanism of action. Let us suppose, as a purely hypothetical case, that this consists in the decreased activity of an enzyme, both the unknown and cortisone acting on the same enzyme to alter its activity. If however, different mechanisms were involved in the anti-rheumatic effects of the steroids, then their effects might even be antagonistic and this method of comparison would not be valid.

Practical Application.-The anti-rheumatic activity of testosterone, pregnenolone, and acetoxypregnenolone* have been tested by the above method.

A series of patients, carefully selected as outlined above, is brought into a state of " minimal disease activity" by means of a dose of cortisone just below that required to control the disease; the unknown steroid is then added, and its minimal effectivity assessed. Thus the third and perhaps the fourth of the variables listed above is controlled. If the drug under test is unable to reverse the minimal disease activity it can be assumed that it has no cortisone-like anti-rheumatic action.

\footnotetext{
* The cortisone, pregnenolone, and acetoxypregnenolone were all aqueous crystalline suspensions.
} 


\section{Procedure}

Out of fifty cases seen in the Arthritis Clinic of the Out-Patient Department of the Royal Victoria Hospital, Montreal, five rheumatoid arthritis patients were selected who fulfilled the criteria discussed above:

(1) they had unremitting rheumatoid arthritis activity,

(2) the erythrocyte sedimentation rate remained abnormally high,

(3) they had been seen weekly in the Out-Patient Department for a period of 2 to 10 years before the present study was undertaken,

(4) their previous response to other forms of therapy was known,

(5) they all had the most severe type of rheumatoid arthritis.

During these investigations the patients were seen daily by the writer, and the erythrocyte sedimentation rate was determined, at first daily and then three times per week. Blood electrolyte and proteins were determined, and urinary 17-ketosteroid, glucocorticoid, and other determinations made from time to time, as the clinical course indicated.

A complete physical examination was made daily and the subjective pain experienced by the patient during the previous 24 hours was denoted as:

$$
\begin{aligned}
& + \text { minimal, } \\
& ++ \text { moderate, } \\
+ & ++ \text { severe but bearable } \\
++ & + \text { unbearably severe. }
\end{aligned}
$$

This method took into account the degree of articular swelling, range of jointmotion (tested in the Physiotherapy Department), and muscle function (e.g., tests with the hand dynamometer in the Neurological Department). The cases were also assessed according to the classification accepted by the New York Rheumatism Association and American Rheumatism Association (Steinbrocker and others, 1949).

The data given below cover a period of 10 months' clinical study. The patients' reactions to various types and intervals of dosage are presented in great detail so that the niceties of the grades of remission and exacerbation which resulted may be observed. The treatment, sedimentation rate, and severity of symptoms in Cases 1, 2, and 3 are set out graphically in the three Figures.

\section{Case Reports}

Case 1 (F.2371, see Fig. 1). - 28-year-old male, with 10-years' history of rheumatoid arthritis of a slowly progressive type which had remained continuously active with -one or more joints acutely involved during the entire time.

Disease Activity.-The tarsal and metatarsal joints were involved first, the disease gradually progressing until the patient was unable to walk unassisted. There were typical $x$-ray changes in the involved joints, with osteoporosis and narrowing and clouding of the joint spaces. There had been varying disease activity in both knees with soft-tissue swelling, and at the time of the experiment there was an accumulation of fluid in both knee joints, and in the right quadriceps muscle giving the knee the size and shape of a football. Both wrists were ankylosed with involvement of all the carpal and metacarpal bones; there were typical $x$-ray changes and gross deformities of the hands with ulnar deviation and muscle atrophy. There was acute pain in both 
wrists but little swelling. The third proximal interphalangeal joint of the right hand showed acute swelling, redness, and pain. Both elbow joints showed swelling, pain, tenderness, and limitation of extension to $45^{\circ}$. There was extreme muscle atrophy throughout the body, which was especially marked in the upper and lower limbs.

Appearance.-This patient has eunuchoid proportions with short trunk, and long upper and lower extremities. The hands and feet are gracile and elongated, size 14 shoe. He has never had to shave, there is scant axillary and pubic hair, and no hair on the trunk and extremities.

History.-The patient had been observed weekly in the out-patient department arthritis clinic for 5 years, during which the sedimentation rate varied from 14 to $28 \mathrm{~mm}$. with only occasional normal values. At all times during this five-year period the patient had unremitting signs and symptoms of active rheumatoid arthritis.

Laboratory Findings.-Serum electrolytes normal with sodium at lower limit of normal $317 \mathrm{mg}$. per cent. (normal 320-340).

Urinary $17-$ ketosteroid excretion $7.6 \mathrm{mg}$. $24 \mathrm{hrs}$ (normal 5-10); glucocorticoids 30 glycogenic units $/ 24 \mathrm{hrs}$ (normal $40-80$ ); gonadotropins positive at $52 \cdot 8 \mu$, stimulated at $105 \cdot 6 \mu$ (normal, positive at 26 ).

Oestrogen positive at $80 \mu$, stimulated at $160 \mu$ (normal 40-60).

Increased tolerance to glucose, fasting $74 \mathrm{mg}$. per cent., $\frac{1}{2} \mathrm{hr} 105,1 \mathrm{hr} 85,1 \frac{1}{2} \mathrm{hrs} 95,2 \mathrm{hrs} 89$, $2 \frac{1}{2}$ hrs 99 (flat-type curve seen in Addison's disease, etc.).

Serum total cholesterol low, $123 \mathrm{mg}$. per cent. (normal 150-250).

Haemoglobin 73 per cent.

Red blood count $3,750,000$.

Assessment.-At the start of the present study (January 26, 1950) the disease activity was $+^{\prime}++$, with continuous severe pain in the involved joints, the patient being able to sleep only a few hours at night. He was unable to walk unassisted and unable to stand in the morning, having to be assisted from the bed to the bath. Elbows, feet, and ankles were all acutely active. A large amount of fluid was detectable in the left knee and surrounding soft tissues. Sedimentation rate 16 (corrected Wintrobe). This patient was classified as "Stage 4, active, Class 4 ".

Therapy.-This patient first received testosterone propionate solution in oil intramuscularly twice weekly, Injection 1-200 mg., 2-250 mg., 3-500 mg., 4-200 mg., 5-250 mg. There was no cessation of pain, no change in swelling, heat, redness, or tenderness in the involved joints. The sedimentation rate during the second week fell from an initial value of $16 \mathrm{~mm}$. (uncorrected 23), to $11 \mathrm{~mm}$. (uncorrected 17). During the second week, the left ankle joint became more severely painful; there was increase in swelling and pain in the right knee joint, and severe pain in the elbow and hands in the mornings. The patient was objectively and subjectively worse; therefore therapy was discontinued (Grade 4 response).

After one week without treatment the sedimentation rate rose to $20 \mathrm{~mm}$. (uncorrected 27). Ascorbic acid was then given, $1 \mathrm{~g}$. $/ 24 \mathrm{hrs}$, intravenously, after which a decrease of fluid in the right knee was observed; this was now barely detectable but remained as before in the right quadriceps. Upon repeated injections of ascorbic acid $1 \mathrm{~g}$. there was no change in pain or other symptoms, or in the inflammation in the involved joints.

The patient was then given $10 \mathrm{mg}$. DOCA in oil intramuscularly, followed by $1 \mathrm{~g}$. ascorbic acid intravenously. After the second daily injection there was no palpable fluid in the right knee joint. There was also great subjective improvement, the patient commenting that he was able to dress himself in the morning for the first time for many years and was able to walk unassisted on rising in the morning. However, the sedimentation rate remained elevated, $16 \mathrm{~mm}$. (uncorrected 24). There was no pain in the ankles or feet. No further therapy was given after the second injection and the patient's pains and other signs and symptoms of rheumatoid arthritis returned as before.

This time $250 \mathrm{mg}$. testosterone was given intramuscularly and $1 \mathrm{~g}$. ascorbic acid. 


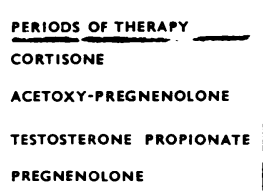

SEDIMENTATION RATE
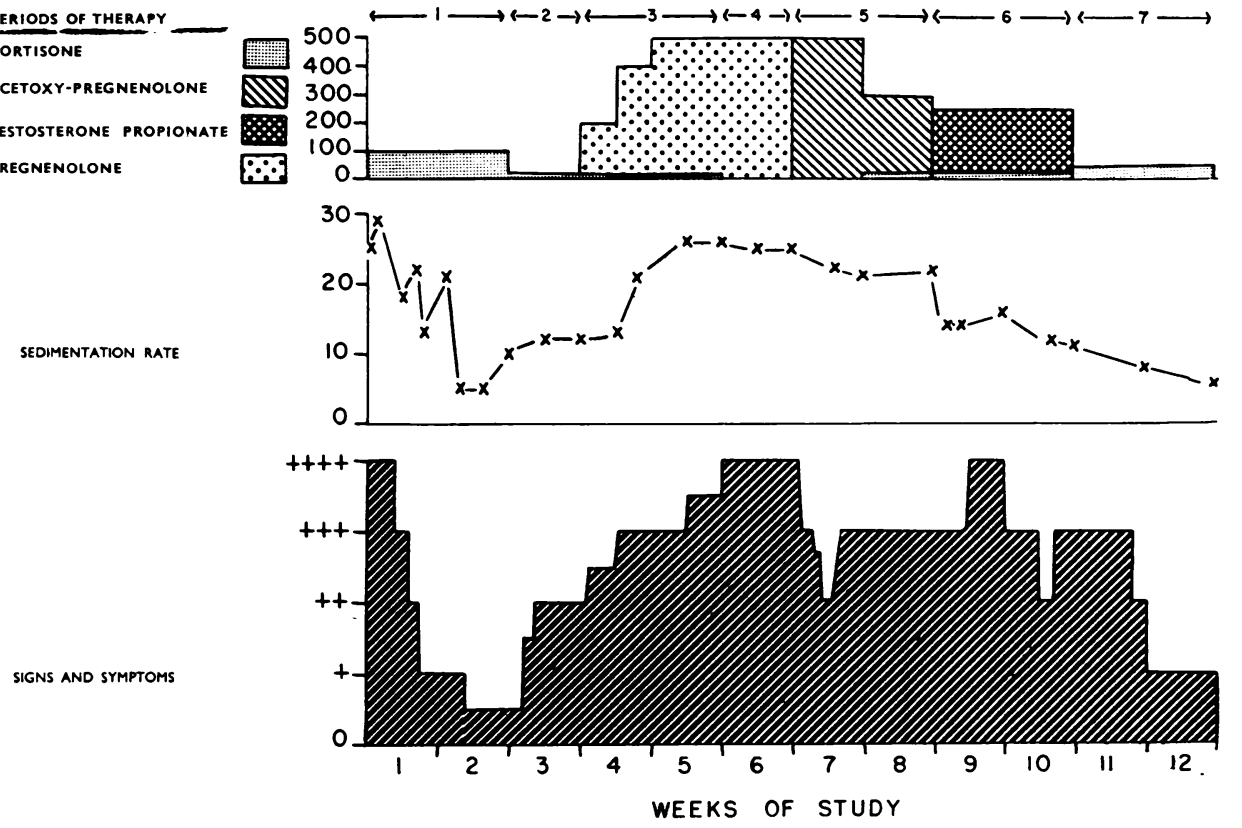

FIG. 1.-Case 1 (F.2371), rheumatoid arthritis.

Periods of therapy:

(1) Disease controlled on cortisone acetate $100 \mathrm{mg}$. $/ 24 \mathrm{hrs}$.

(2) Cortisone $25 \mathrm{mg} . / 24 \mathrm{hrs}$. Minimal disease activity.

(3) Simultaneous administration of pregnenolone $200,400,500 \mathrm{mg} . / 24 \mathrm{hrs}$. No beneficial effect.

(4) Cortisone discontinued. Pregnenolone $500 \mathrm{mg} / 24 \mathrm{hrs}$. Severe exacerbation.

(5) Acetoxypregnenolone $500 \mathrm{mg} . / 24 \mathrm{hrs}$. Little beneficial effect until re-institution of $25 \mathrm{mg}$. cortisone.

(6) Simultaneous administration of $25 \mathrm{mg}$. cortisone and testosterone propionate $250 \mathrm{mg} . / 24 \mathrm{hrs}$. No beneficial effect.

(7) Cortisone $50 \mathrm{mg} . / 24 \mathrm{hrs}$. Remission.

$24 \mathrm{hrs}$ later there was only minimal pain in the involved joints and the patient was again able to walk unassisted. After the third injection testosterone was discontinued and ascorbic acid $1 \mathrm{~g}$. $/ 24 \mathrm{hrs}$ was given intravenously for one week, at the end of which he felt subjectively improved with absence of pain in the elbows and hands, and greater range of movement in the fingers, but residual pain remained in the involved joints on active motion and a small amount of fluid remained in the right quadriceps muscle. However, several involved joints were acutely active, with severe pain, including the second and third proximal interphalangeal joints of the right hand and both elbows (Grade 3 response).

After a two-week control period, there was ++++ activity in all the involved joints, with severe, constant, unbearable pain, requiring frequent analgesics. He was unable to walk because of severe pain and swelling in the knee and ankle joints, and severe pain in both heels. The right calf muscles were markedly oedematous, and it was possible to depress the quadriceps muscle 2 inches with the ruler.

Fig. 1 (1). He was next put on cortisone acetate in aqueous suspension $-100 \mathrm{mg}$. $/ 24 \mathrm{hrs}$ intramuscularly. The sedimentation rate at the beginning of cortisone therapy was $26 \mathrm{~mm}$. (uncorrected 38), and on the second day of therapy $30 \mathrm{~mm}$. (uncorrected 47). After the third injection of cortisone there was some objective and subjective improvement, and patient was able to stop taking analgesics and to sleep better. There was almost 
complete disappearance of swelling in the right knee but no change in the quadriceps. After 5 days of cortisone therapy, heat and tenderness disappeared from the right knee. There was now $10^{\circ}$ flexion in the left wrist, whereas it was motionless before. Swelling in the ankles had completely disappeared, the patient being able to walk half a mile with only moderate pain, and there was a $20^{\circ}$ range of flexion of the ankles, but 1 inch of palpable fluid remained in the quadriceps. After one week there was only + disease activity in the involved joints with minimal residual pain, swelling, and tenderness, and on the 10th day there was further improvement, the patient being able to run for the first time since the onset of his disease and to walk vigorously for a mile and a half. On the eighth day the sedimentation rate was still elevated $(21 \mathrm{~mm}$., uncorrected 34$)$, but on the ninth day it fell to normal values (6 mm., uncorrected 16$)$.

At the end of the second week there were only minimal residual signs and symptoms of rheumatoid arthritis and the sedimentation rate was normal (Grade 1 response, i.e., complete remission).

Fig. 1 (2). During the third week the dose was reduced to $25 \mathrm{mg} . / 24 \mathrm{hrs}$, and on the third day a little palpable fluid returned in the right knee, with moderate pain in the involved joints on active motion. Thus the disease activity was + (i.e., equal to minimal disease activity) on cortisone $25 \mathrm{mg}$. $/ 24 \mathrm{hrs}$. The sedimentation rate had risen to $12 \mathrm{~mm}$. (uncorrected 22), but the patient was sleeping well, without analgesics.

Fig. 1 (3). To find whether pregnenolone, acetoxypregnenolone, or testosterone could reduce this minimal disease activity, cortisone $25 \mathrm{mg}$. $/ 24 \mathrm{hrs}$ was continued during the fourth and fifth weeks, but combined with pregnenolone crystalline in aqueous suspension intramuscularly $200-500 \mathrm{mg}$. $/ 24 \mathrm{hrs}$. Despite the large dose of pregnenolone given in combination with cortisone, an acute exacerbation occurred, with severe pain in elbows, knees, ankles, and feet, and the patient became bed-ridden. His knees and ankles were swollen and inflamed, and the swelling and tenderness in the elbows were more severe than before treatment.

Fig. 1 (4). During the sixth week he was given pregnenolone $500 \mathrm{mg} . / 24 \mathrm{hrs}$; the arthritis activity was ++++ and the patient was unable to sleep because of severe pain; the objective and subjective changes in the involved joints indicated a severe exacerbation (Grade 4 response).

Fig. 1 (5). In the seventh week he received acetoxypregnenolone intramuscularly 300$500 \mathrm{mg}$. $/ 24 \mathrm{hrs}$. The sedimentation rate had risen during the sixth week to $25 \mathrm{~mm}$. (uncorrected 36). During the eighth week this was combined with cortisone $25 \mathrm{mg} . / 24 \mathrm{hrs}$, and there was some decrease in the severity of the objective and the subjective findings, but inflammatory signs in the involved joints were unchanged. There was much palpable fluid in the right knee and quadriceps muscle, with constant severe pain in the knees, ankles, and elbows. The sedimentation rate remained elevated $(22 \mathrm{~mm}$., uncorrected 35$)$. Subcutaneous nodules in the region of both elbows were noted for the first time. The patient complained that the pain in his elbows was worse during acetoxypregnenolone therapy (Grade 4 response).

Fig. 1 (6). During the ninth and tenth weeks testosterone propionate $250 \mathrm{mg}$. $/ 24 \mathrm{hrs}$ was given intramuscularly with the cortisone $25 \mathrm{mg} . / 24 \mathrm{hrs}$. After the fourth injection of testosterone there was a severe exacerbation with ++++ arthritis activity. The elbows, ankles, and feet were severely painful and swollen, and the patient was unable to walk, to care for himself, or to sleep. The sedimentation rate at this time, however, had returned to normal $(6 \mathrm{~mm}$., uncorrected 16). During the second week of combined testosterone and cortisone therapy, swelling in the involved joints subsided but the pain continued to be severe and constant. The subcutaneous nodules were larger, and he complained that he had more pain in his wrists and fingers than previously. There was much palpable fluid in the right knee and right quadriceps, seborrhoeic acne of the nose and surrounding tissue. At the end of the tenth week the sedimentation rate remained 
normal (11 mm., uncorrected 25$)$, but the signs and symptoms of rheumatoid activity were more severe than when on $25 \mathrm{mg}$. cortisone alone (Grade 4 response).

Fig. 1 (7). Testosterone was then discontinued and the cortisone increased to $50 \mathrm{mg}$./ $24 \mathrm{hrs}$. There was no change until the end of the second week when the pain diminished progressively until the 17 th day, when there were only residual pains in the involved joints, especially in the ankles, on active motion. Because of these slight pains the patient was unable to walk as well as when he was on cortisone $100 \mathrm{mg}$. $/ 24 \mathrm{hrs}$, but at rest he was symptomless; he could care for himself, walk to the hospital, and engage in limited social activities.

To decrease the visits to the out-patient department, $100 \mathrm{mg}$. cortisone was given every other day, but at the end of the third week of this regime, moderate pain and swelling returned in the knees and ankles, and walking became more difficult. After 6 weeks of injections every other day the fluid in the right quadriceps and knee joint was as abundant as ever and frequent analgesics were required.

During the seventh and eighth weeks $100 \mathrm{mg}$. cortisone was given every day, but the exacerbation continued and severe pain extended to the elbow and wrists, but at the end of the eighth week he once again became symptom-free, which indicates that daily administration of cortisone is required in this case to maintain remission. He has since been maintained symptom-free with only occasional pain for 2 months on a daily dose of $50 \mathrm{mg}$. cortisone intramuscularly, but it seems necessary in this case to continue daily cortisone injections indefinitely.

Case 2 (C.5296, see Fig. 2).-55-year-old male, with rheumatoid arthritis of 12 years' duration. He had been observed in the arthritis clinic weekly for 6 years except when admitted to the Royal Victoria Hospital in 1946 and 1949.

Disease Activity.-The rheumatoid arthritis had progressed slowly and continuously involving joints of the feet, ankles, knees, hands, wrists, and shoulders. The musculature was generally well preserved with little local atrophy. Arthritis of the wrists, ankles, knees, hands, and shoulders had remained active during the entire time of observation, with moderate to severe pain, swelling, and limitation of motion. The wrists were immobile without bony ankylosis, and the knees swollen and acutely painful and tender.

History.-There had been no response to previous treatment, including gold and physiotherapy. The sedimentation rate had remained elevated (24 to $40 \mathrm{~mm}$., corrected Wintrobe). The patient had recently been hospitalized at the Royal Victoria Hospital and treated with ACTH for one week $(100 \mathrm{mg}$. $/ 24 \mathrm{hrs})$ with disappearance of all pain and swelling and return of use of the involved joints.* Upon withdrawal of ACTH, his condition became exacerbated.

Special Diet.-At the start of this present study the patient was placed on a special high protein, low calorie diet, to elicit an increased adrenocortical secretion. Before treatment the 17-ketosteroid urinary excretion and glucocorticoid excretion had been low. The diet consisted of 1,800 to 2,000 calories per day, 300-400 g. protein per day. Synthetically flavoured gelatine made up a large fraction of the protein in addition to food with a high protein content (which alone is too high in calories). Supplementary vitamins and essential amino-acids were added.

Laboratory Findings.-Daily urinary excretion of 17-ketosteroids had ranged from 4 to $10 \cdot 8$ mg. $/ 24 \mathrm{hrs}$, with one isolated finding at $15 \cdot 2 \mathrm{mg} . / 24 \mathrm{hrs}$; but during the first week of high-protein diet there was no significant rise and 17-ketosteroid excretion varied from 4.6 to $10.6 \mathrm{mg}$. $/ 24 \mathrm{hrs}$; during the second week there was a peak at $13.3 \mathrm{mg} . / 24 \mathrm{hrs}$, and during the third week a peak at $16.4 \mathrm{mg} . / 24 \mathrm{hrs}$. The glucocorticoid excretion level in this patient had been low (16 and 19 glycogenic units/24 hrs, normal 40 to 80 ), but during the high-protein diet period this rose to 32 and 40 glycogen units $/ 24$ hrs. A paradoxical finding in glucocorticoid excretion occurred subsequently while the patient was on testosterone $100 \mathrm{mg} . / 24 \mathrm{hrs}$; on the third and fourth day,

* This ACTH study is reported elsewhere. 
during which times there was no clinical improvement in the rheumatoid arthritis, the glucocorticoid excretion rose to 72 glycogen units/24 hrs. During an exacerbation of the disease in this patient the glucocorticoid level was higher than it was during a remission induced by ACTH (exacerbation level, 69 and 65 glycogen units/24 hrs; remission level, 26, 48, and 30 glycogen units/24 hrs).*

Assessment.-After cessation of the special diet there was a 4-week control period during which the inflammation in the involved joints remained severe and the sedimentation rate rose to $38 \mathrm{~mm}$. (uncorrected 40 ). The patient complained of severe pains in the wrists, elbows, and knees (disease activity +++ ). He was able to perform only the minimal activities of self care and to hobble with the aid of a cane. This patient was classified as "Stage 3, active, Class 3 ".

Therapy.-He was placed on $250 \mathrm{mg}$. testosterone propionate intramuscularly twice a week. There was an immediate improvement in ability to walk for several hours after each injection, when the patient was able to " throw away his cane". This was very likely a " psychogenic improvement ", since after the fourth injection the degree of inflammation of the joints was ++++ , he was unable to move his ankles, and there was an increase in joint fluid and signs of inflammation. Extreme pain and swelling continued in the wrists and shoulders, the patient was unable to walk, and the sedimentation rate remained high $(26 \mathrm{~mm}$.); thus testosterone therapy was discontinued. At this time he was unable to bear weight on standing without ++++ pain.

To investigate the temporary post-injection improvement which followed testosterone, the patient was told he was to receive a combination therapy and was given one injection of distilled water intravenously and one intramuscularly. Ten minutes after injection he was able to walk without his cane, with only a moderate amount of pain, and greatly increased range in motion and freedom of movement in both knees.

He then received DOCA $5 \mathrm{mg}$. intravenously simultaneously with $1 \mathrm{~g}$. ascorbic acid intramuscularly, after which there was no change in signs or symptoms beyond that which had occurred with distilled water. The same evening, 6 hours after the placebo, signs and symptoms returned to ++++ .

During a one-week control period the signs and symptoms remained ++++ , with severe pain and inflammation in the involved joints, and sedimentation rate moderately elevated (14 mm., uncorrected 16$)$.

He then received a combined daily injection of $5 \mathrm{mg}$. DOCA and $1 \mathrm{~g}$. ascorbic acid intramuscularly, one week after which there was no subjective or objective change in signs or symptoms ++++ , and the sedimentation rate remained elevated $(22 \mathrm{~mm}$., uncorrected 20). However, on several occasions there was temporary subjective relief of symptoms for 6 hours after injection equal to that which occurred after the placebo and testosterone injections. The amount of palpable fluid in the knees and wrist was unchanged (Grade 4 response).

Fig. 2 (1). He was then placed on cortisone acetate in aqueous suspension intramuscularly $100 \mathrm{mg}$. $/ 24 \mathrm{hrs}$. On the fifth day the pain in the knees was present moderately only on active motion $(++)$, and there was only minimal residual pain in the right shoulder, hand, and right wrist $(+)$. The sedimentation rate at this time remained elevated $(28 \mathrm{~mm}$., uncorrected 26). On the ninth day the sedimentation rate had fallen to normal $(5 \mathrm{~mm}$.). At this time he was walking normally without his cane, and except for slight residual stiffness in the joints was free of signs and symptoms of rheumatoid arthritis (Grade 1 response). No significant changes occurred in the laboratory findings during cortisone therapy, and the glucose tolerance curve showed hypoglycaemic levels after $2 \frac{1}{2}$ hours (fasting, $87 \mathrm{mg}$; $\frac{1}{2} \mathrm{hr}, 144 ; 1 \mathrm{hr}, 126 ; 2 \frac{1}{2} \mathrm{hrs}, 47$ ). The patient was now working 12 hours daily in his store and walking several miles without pain.

* With regard to glucocorticoid excretion levels in chronic rheumatoid arthritis, Venning and others (1951) found the average excretion levels to be considerably lower than normal, but three cases with acute onset had increased glucocorticoid excretion. 
PERIODS OF THERAPY

CORTISONE

PREGNENOLONE

ACETOXY-PREGNENOLONE

TESTOSTERONE PROPIONATE
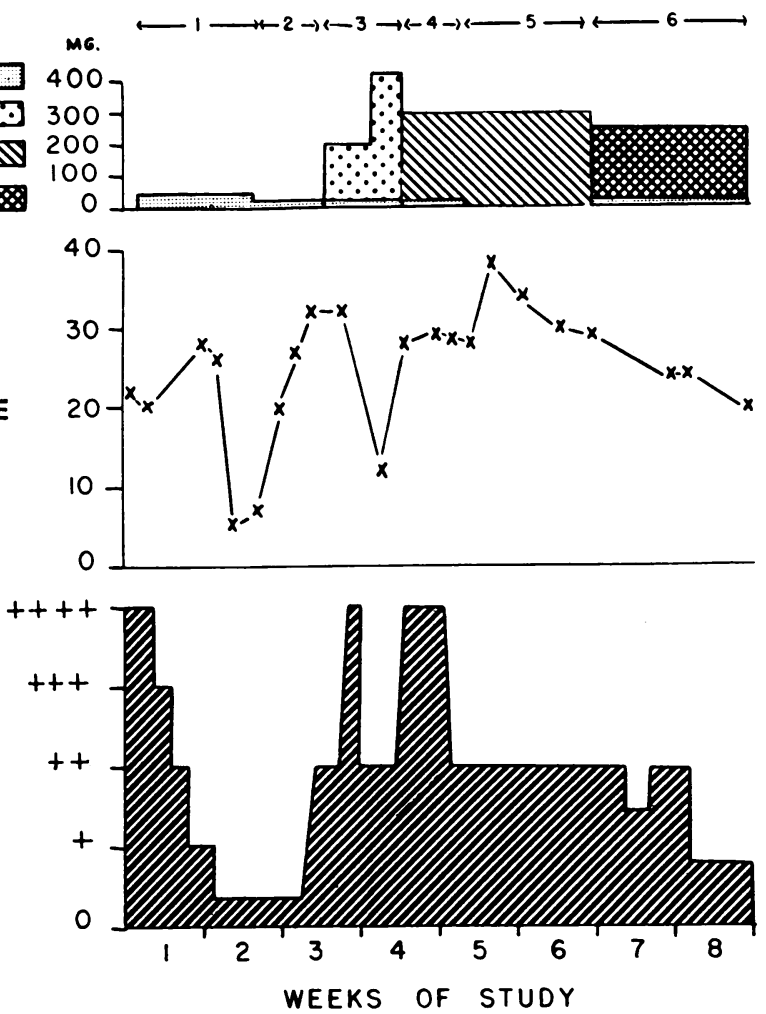

FIG. 2.-Case 2 (C.5296), rheumatoid arthritis.

Periods of therapy:

(1) Disease controlled on cortisone acetate $50 \mathrm{mg}$. $/ 24 \mathrm{hrs}$.

(2) Cortisone $25 \mathrm{mg} / 24 \mathrm{hrs}$. Minimal disease activity.

(3) Simultaneous administration of pregnenolone 200 and $400 \mathrm{mg} . / 24 \mathrm{hrs}$. Severe exacerbation.

(4) Simultaneous administration of acetoxypregnenolone $300 \mathrm{mg} / 24 \mathrm{hrs}$. No beneficial effect.

(5) Cortisone discontinued and acetoxypregnenolone continued. No beneficial effect.

(6) Cortisone $25 \mathrm{mg} / 24 \mathrm{hrs}$ and testosterone propionate $250 \mathrm{mg}$. $/ 24 \mathrm{hrs}$. Some improvement, but remission not achieved.

Fig. 2 (2). To find whether the failure of response to testosterone, DOCA, and ascorbic acid was due to the severity of the rheumatoid arthritis, the dose of cortisone was reduced to $25 \mathrm{mg} . / 24 \mathrm{hrs}$. On the $3 \mathrm{rd}$ day of this reduced dosage there was a mild return of signs and symptoms, and the sedimentation rate rose to $20 \mathrm{~mm}$. (uncorrected 13), and on the sixth day to $30 \mathrm{~mm}$. (uncorrected 28). At this time there was moderate pain, swelling, tenderness, and heat in the right knee and both heels which prevented walking except with a cane, but other joints previously involved were symptomless, and the patient found it necessary to take analgesics only twice daily. The disease activity was now considered moderate, ++ (Grade 3 response).

Fig. 2 (3). To find whether other steroids were capable of reversing this minimal degree of disease activity, cortisone $25 \mathrm{mg}$. $/ 24 \mathrm{hrs}$ was continued, with the addition of pregnenolone intramuscularly $200 \mathrm{mg} . / 24 \mathrm{hrs}$ for 5 days. The sedimentation rate fell from $32 \mathrm{~mm}$. to $12 \mathrm{~mm}$., but the joint pain and swelling became greatly aggravated, so that the patient was unable to walk. The dose of pregnenolone was then increased to $400 \mathrm{mg} . / 24 \mathrm{hrs}$ 
(in combination with cortisone $25 \mathrm{mg}$./24 hrs) for 3 more days, after which the sedimentation rate had risen to $28 \mathrm{~mm}$., and the joint swelling, pain, and inflammation had become more severe than pre-treatment. The patient was now bed-ridden or brought to the clinic in a wheel chair, ++++ (Grade 4 response), and his condition was worse than when maintained on cortisone $25 \mathrm{mg}$. $/ 24 \mathrm{hrs}$ alone.

Fig. 2 (4). Acetoxypregnenolone in aqueous crystalline suspension intramuscularly 300 mg./24 hrs was substituted for pregnenolone, and given in combination with cortisone $25 \mathrm{mg}$. $/ 24 \mathrm{hrs}$. The sedimentation rate continued to rise until on the 10 th day it was $38 \mathrm{~mm}$. (uncorrected 43), but the patient's clinical condition, was the same as on cortisone $25 \mathrm{mg} . / 24 \mathrm{hrs}$ alone. There was fluid, heat, and redness in the right knee and ankle, and moderate pain on active movement $(++)$.

Fig. 2 (5). When cortisone was stopped and acetoxypregnenolone $300 \mathrm{mg}$. $/ 24 \mathrm{hrs}$ continued there was no detectable change either in sedimentation rate or in signs and symptoms. No significant changes occurred in other laboratory findings, and the glucose tolerance curve remained as pre-treatment. On the 22nd day of acetoxypregnenolone therapy the patient's condition was unchanged and the sedimentation rate remained abnormally elevated at $31 \mathrm{~mm}$.

Treatment was then withdrawn for a 10-day period without change in signs and symptoms or sedimentation rate.

Fig. 2 (6). Testosterone propionate $250 \mathrm{mg}$. $/ 24 \mathrm{hrs}$ intramuscularly was then given with cortisone $25 \mathrm{mg} . / 24 \mathrm{hrs}$. There was subjective and objective improvement, the patient being able to walk without his cane and having only slight pain in the right knee, but the sedimentation rate remained elevated $(20 \mathrm{~mm}$.).

Injections of distilled water were then substituted for one week, on the fifth day of which the sedimentation rate had risen to $26 \mathrm{~mm}$. (uncorrected 38) with a return of severe pain and swelling in knee and ankle joints $(+++)$.

At this time cortisone acetate $50 \mathrm{mg} . / 24 \mathrm{hrs}$ was given, and after 2 weeks on this dose the patient was symptom-free, and the sedimentation rate had returned to normal (10 mm., uncorrected 12 ), with only slight residual pain in the wrists and ankles on strenuous activity.

After three weeks of this minimal effective dose a placebo was substituted, and in one week signs and symptoms returned, with moderately severe swelling and inflammation in ankles and knee joints and elevation of the sedimentation rate to $26 \mathrm{~mm}$.

Testosterone $250 \mathrm{mg}$. with cortisone $25 \mathrm{mg}$. $/ 24 \mathrm{hrs}$ was thus not as effective as cortisone $50 \mathrm{mg} . / 24 \mathrm{hrs}$ alone. The latter caused complete remission, and the former only slight improvement without reduction in the sedimentation rate. The minimal degree of disease activity was not reversed by pregnenolone, acetoxypregnenolone, or testosterone.

Case 3 (F.2619, see Fig. 3). -48-year-old white male, with rheumatoid arthritis of 13 years' duration.

Disease Activity.-The disease has slowly progressed to involve the joints of the hands, wrists, elbows, ankles, feet, and knees with typical deformities in the hands, including subluxation of the proximal interphalangeal joints. There was bony ankylosis of both wrists and acute inflammatory signs and symptoms in all the involved joints, especially in the elbows, shoulders, and knees, which prevented all activity except minimal self care.

History.-Other pertinent features of this case were the occurrence of hyperthyroidism with thyroidectomy performed 3 years after the onset of rheumatoid arthritis. No improvement in the arthritic signs and symptoms had followed, but subsequently there had been onset of exophthalmos of a non-progressive type. The basal metabolism rate had since remained within normal limits. Amongst the laboratory findings was a disturbed carbohydrate regulation with decreased glucose tolerance to be discussed later. The patient also had a history of gastric ulcer for which a subtotal gastrectomy had been 
performed in 1947. There were dark, pigmented, yellowish-brown areas, especially on the face and elbow, but no pigmentation of the buccal mucosa.

Laboratory Findings.-Blood pressure 128/86.

Serum electrolyte normal range.

Red blood count $3,000,000$, normal differential.

Abnormally low urinary 17 -ketosteroid excretion of $3.4 \mathrm{mg}$. $/ 24 \mathrm{hrs}$; gonadotropins-abnormally high, positive at a $105 / 24 \mathrm{hrs}$.

During a 5-year pre-treatment period, the sedimentation rate had remained abnormally elevated (14 to $20 \mathrm{~mm}$.), and the arthritic signs and symptoms in the involved joints had remained active during this period.

Assessment.-At the beginning of treatment, the degree of disease activity was ++++ , and the patient was classified as "Stage 4, active, Class 3 ".

Therapy.-He was placed on testosterone propionate in oil solution intramuscularly $250 \mathrm{mg}$. twice a week. After the second injection there was immediate objective and subjective improvement, arthritis activity decreasing to ++ with improved movement of all involved joints and decrease of pain to moderate. During the third week of therapy, the pain and arthritis signs and symptoms returned to pre-treatment levels, but by the end of the week there was cessation of all pain, and free movement in joints where there was no fibrous or bony ankylosis. The sedimentation rate had now fallen from $20 \mathrm{~mm}$. (uncorrected 39 ) to $11 \mathrm{~mm}$. (uncorrected 13 ), and remained essentially normal during the fourth and fifth weeks of therapy. The patient felt stronger, was almost entirely free from pain, and expressed a desire to return to work. This may be classified as Grade 2 response. There was a $6 \frac{1}{2}-\mathrm{lb}$. weight gain during testosterone therapy. There was, however, no change in laboratory findings, the glucose tolerance curve before treatment was fasting, $90 \mathrm{mg}$; $\frac{1}{2} \mathrm{hr}, 213 ; 1 \mathrm{hr}, 288 ; 1 \frac{1}{2} \mathrm{hr}, 258 ; 2 \mathrm{hrs}, 140 ; 2 \frac{1}{2} \mathrm{hrs}, 80 \mathrm{mg}$. After the fifth week of testosterone therapy the curve was fasting, $99 \mathrm{mg}$.; $\frac{1}{2} \mathrm{hr}, 238 ; 1 \mathrm{hr}, 266 ; 1 \frac{1}{2} \mathrm{hrs}, 107$; $2 \frac{1}{2} \mathrm{hrs}, 35$. Thus there was essentially no change, there being an elevated plateau 1-1 $\frac{1}{2}$ hours, and hypoglycaemic levels at $2 \frac{1}{2}$ and $3 \frac{1}{2}$ hours, both before and after treatment. There was no change in the exophthalmos during testosterone therapy; nor in the elevated gonadotropins, which remained positive at 105 glycogenic units/24 hrs.

To determine the effects of desoxycorticosterone acetate on the decreased glucose tolerance and on the arthritis signs and symptoms, DOCA intramuscularly $10 \mathrm{mg}: / 24 \mathrm{hrs}$ was given for one week, during the last 3 days of which $1 \mathrm{~g}$. ascorbic acid intravenously was given simultaneously. During this week there was no change in signs or symptoms as compared with the pre-treatment period. The sedimentation rate remained normal as during testosterone therapy $(9 \mathrm{~mm}$., uncorrected 30$)$. The glucose tolerance was increased, but not above the usual range of variability of this test: fasting, $85 \mathrm{mg}$.; $\frac{1}{2} \mathrm{hr}, 190 ; 1 \mathrm{hr}, 184 ; 2 \mathrm{hrs}, 95 ; 2 \frac{1}{2} \mathrm{hrs}, 53$. After a one-week control period a combined glucose-insulin tolerance test showed a return to decreased glucose-insulin tolerance and also insulin resistance, fasting, $87 \mathrm{mg}$; $\frac{1}{2} \mathrm{hr}, 225 ; 1 \mathrm{hr}, 219 ; 2 \mathrm{hrs}, 95 ; 3 \mathrm{hrs}, 53$. At this time the disease activity of rheumatoid arthritis had returned to +++ , with severe pain and swelling in the right knee preventing walking. Severe pain also recurred in the left shoulder and proximal interphalangeal joints of the left hand.

Fig. 3 (1). Cortisone acetate $100 \mathrm{mg}$. $/ 24 \mathrm{hrs}$ was given intramuscularly. At the beginning of therapy the sedimentation rate was elevated (14 mm., uncorrected 33). After 3 days there was no change in signs and symptoms, the patient could not sleep because of pain requiring frequent analgesics, and was unable to stay on his feet on account of pain in the knees and weakness. On the fourth day, however, arthritis activity had fallen to + with only minimal pain in the right knee, and shoulder joints, and left hand. Swelling in the right knee had markedly diminished and by the fifth day was barely detectable. On the ninth day the sedimentation rate had fallen to normal $(0 \mathrm{~mm}$., uncorrected 14$)$. The left hand which had been immobile, fixed in a grasping position, was now mobile with little 
PERIODS OF THERAPY

DOCA

CORTISONE

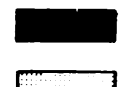

PREGNENOLONE $\because \because \cdots$

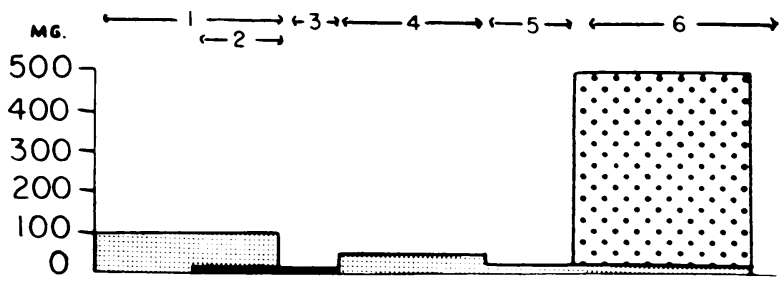

SEDIMENTATION RATE



SIGNS AND SYMPTOMS

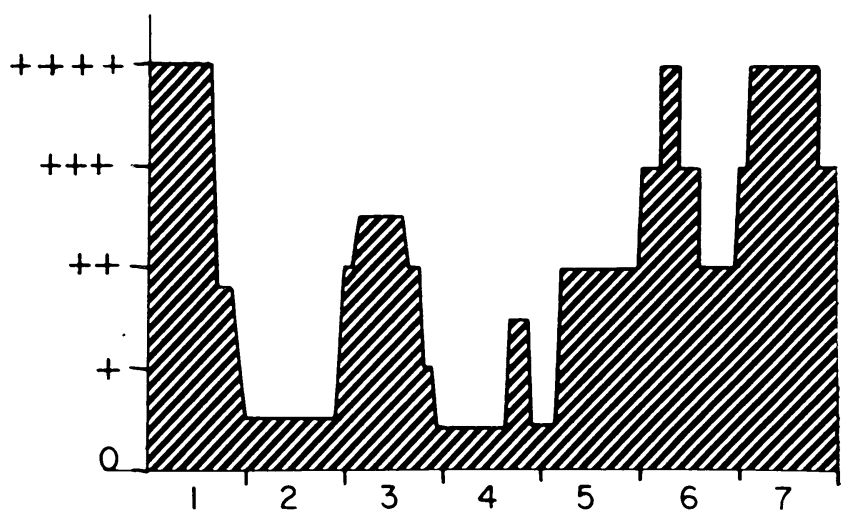

WEEKS OF STUDY

FIG. 3,-Case 3 (F.2619), rheumatoid arthritis.

Periods of therapy:

(1) Disease controlled on cortisone acetate $100 \mathrm{mg} .24 \mathrm{hrs}$,

(2) Simultaneous administration of DOCA $10 \mathrm{mg}$. No effect.

(3) Cortisone discontinued. DOCA continued. Immediate exacerbation.

(4) Disease controlled on cortisone $50 \mathrm{mg}$. $24 \mathrm{hrs}$. Minimum effective dose.

(5) Mild exacerbation on cortisone $25 \mathrm{mg}$. $24 \mathrm{hrs}$. Minimal disease activity.

(6) Simultaneous administration of pregnenolone $500 \mathrm{mg} .24 \mathrm{hrs}$. No beneficial effect.

residual stiffness. There was no pain or tenderness in any of the involved joints. On the tenth day the patient contracted a severe head cold and bronchitis with purulent sputum and was put on $1 \mathrm{~g}$. sulphadiazine 4-hourly, but there was no return of signs or symptoms of arthritis.

Fig. 3 (3). During the third week, to find whether desoxycorticosterone acetate would prevent a remission caused by cortisone, DOCA $10 \mathrm{mg} . / 24 \mathrm{hrs}$ intramuscularly was given simultaneously with cortisone $100 \mathrm{mg}$. $/ 24 \mathrm{hrs}$, after which there was no elevation of the sedimentation rate, which remained normal at $10 \mathrm{~mm}$. (uncorrected 35), and no return of 
signs and symptoms of arthritis. The patient was now able to walk vigorously and had only occasional twinges of pain in knee and elbow.

Fig. 3 (3). Cortisone was now stopped and DOCA $10 \mathrm{mg} . / 24 \mathrm{hrs}$ intramuscularly continued. On the second day after the withdrawal of cortisone the signs and symptoms of arthritis recurred, pains were severe, and both elbows became very swollen with large nodules approximately $4 \mathrm{~cm}$. in diameter on the dorsal surfaces. The arthritic activity was now +++ in the involved joints, but the sedimentation rate remained normal $(7 \mathrm{~mm}$., uncorrected 28).

Fig. 3 (4). Because of this severe exacerbation DOCA was stopped on the third day and cortisone $50 \mathrm{mg}$./ $24 \mathrm{hrs}$ begun. On the second day pains and swelling in the involved joints were markedly diminished, and they had disappeared by the third, fourth, and fifth day. During an additional week of cortisone $50 \mathrm{mg}$. $/ 24 \mathrm{hrs}$ there was occasional pain requiring analgesics, and lasting on one occasion 8 to 12 hours. The patient became completely symptom-free after 4 weeks on cortisone $50 \mathrm{mg} . / 24 \mathrm{hrs}$, and the sedimentation rate was normal $(0 \mathrm{~mm}$., uncorrected 15$)$.

Fig. 3 (5). The dose of cortisone was further reduced to $25 \mathrm{mg} . / 24 \mathrm{hrs}$, but on the third day arthritis activity had risen to ++ with a return of swelling and nodules in both elbows and moderate pain in the other involved joints. After one week of this reduced cortisone dosage, the disease activity remained constant at ++ with only moderate changes in the involved joints and minimal swelling. The patient was able to resume his activities, walked vigorously, and had a good appetite, with no systemic signs of arthritis. The sedimentation rate remained normal $(8 \mathrm{~mm}$., uncorrected 24$)$. This was considered a minimal disease activity on cortisone $25 \mathrm{mg}$. $/ 24 \mathrm{hrs}$.

Fig. 3 (6). Pregnenolone crystalline aqueous suspension $500 \mathrm{mg} . / 24 \mathrm{hrs}$ was given with cortisone $25 \mathrm{mg}$./24 hrs to see whether this state of minimal disease activity would be reversed. On the second day of combined pregnenolone cortisone therapy, the signs and symptoms had returned to ++++ with severe exacerbation of pain, swelling in all the involved joints, and marked involvement of the left wrist, +++ . Severe pain prevented the patient from eating or sleeping normally and large amounts of analgesics were required (12 analgesic tablets per day). The exacerbation of signs and symptoms varied from ++ to ++++ during this combined pregnenolone/cortisone therapy, but there was continuous pain requiring analgesics. The sedimentation rate remained elevated (16 mm., uncorrected 26). Severe pain in all the involved joints and marked swelling persisted through the second week of combined therapy and the patient was objectively and subjectively worse than when receiving cortisone alone (Grade 4 response).

Testosterone propionate in oil solution $200 \mathrm{mg}$. $/ 24 \mathrm{hrs}$ intramuscularly was now substituted for pregnenolone/cortisone. Despite the decline of the sedimentation rate to normal values (first week 12, uncorrected 30; second week 10, uncorrected 25), the arthritic activity remained at ++++ during the first week, and +++ during the second week, with severe pain in all involved joints. The patient was unable to walk, dress or care for himself because of pain and swelling in the knee, large subcutaneous nodules in both elbows with swelling, and marked swelling and pain in the left wrist. Frequent analgesics were necessary because of the severe pain, and the patient required a wheel chair for the first time. Thus there was Grade 4 response to testosterone, with no detectable effect on the minimal disease state, although a reduction occurred in the sedimentation rate.

When testosterone was discontinued and cortisone increased to $50 \mathrm{mg}$. $/ 24 \mathrm{hrs}$, the signs and symptoms gradually diminished until there was only minimal residual pain, swelling, and stiffness in the involved joints, i.e. +arthritic activity. The sedimentation rate was normal (10 mm., uncorrected 31), and the major signs of inflammation resolved; thus there was Grade 2 response after one week on cortisone $50 \mathrm{mg}$. $/ 24 \mathrm{hrs}$, which can thus be taken as the minimum effective dose.

Thus cortisone $50 \mathrm{mg} . / 24 \mathrm{hrs}$ for one week rendered the patient symptom free, whereas other steroids in combination with cortisone $25 \mathrm{mg}$. $/ 24 \mathrm{hrs}$ brought on a severe 
exacerbation of signs and symptoms. During a subsequent 4-week period on cortisone $50 \mathrm{mg}$. $/ 24 \mathrm{hrs}$ the patient remained symptom-free except for a flare-up in the 5th carpalmetacarpal joints, where there was acute inflammation, pain, redness, and swelling lasting for 3 days.

After 5 weeks the dose of cortisone was changed from $50 \mathrm{mg} . / 24 \mathrm{hrs}$ to $100 \mathrm{mg}$, every other day with no return of signs and symptoms or rise in sedimentation rate. After 10 weeks, except for an occasional flare-up in the joints lasting one or two days, the patient could be considered in complete remission.

When cortisone was withdrawn exacerbation occurred within one week, and during the second week the sedimentation rate returned to normal levels.

After 10 weeks on cortisone there was no change in weight, blood pressure, glucose tolerance, 17-ketosteroid excretion, or serum electrolyte levels.

More recently the same patient has been maintained on a crystalline suspension of cortisone acetate orally for 12 weeks. The cortisone is taken four times daily and approximately one-third more is required than by the intramuscular route. Methyl testosterone $25 \mathrm{mg} . / 24 \mathrm{hrs}$ orally was added when the patient complained of extreme weakness and malaise. The serum potassium at this time was $14 \cdot 3 \mathrm{mg}$. per cent. (normal $17-21 \mathrm{mg}$. per cent.), and the symptoms diminished within one week with gain in strength and appetite. It is further suggested that potassium chloride 4-6 mg./24 hrs orally, should supplement the dietary potassium intake.

Case 4.-38-year-old male, with psoriasis of 10 years' duration and rheumatoid arthritis for 1 year during which there had been no remission (psoriatic arthritis).

Disease Activity.-The arthritis first involved the wrist and ankle joints, slowly progressing to the shoulders and elbow joints. There were typical $x$-ray changes in the wrists and feet with juxta-articular osteoporosis, and narrowing of the joint spaces, but no ankylosis. The sedimentation rate was consistently elevated, from $31 \mathrm{~mm}$. (uncorrected 45) to $37 \mathrm{~mm}$. (uncorrected 51).

History.-Previous therapy with gold had had no effect, and there had been a $30-\mathrm{lb}$. weight loss in 6 months. Treatment with ACTH prior to the present study had resulted in only slight improvement in the arthritis, with aggravation of the psoriasis which spread to involve the entire trunk, and upon withdrawal of ACTH there had been exacerbation of the rheumatoid arthritis.

Assessment.-The ankles were severely painful and swollen $(+++)$ preventing walking, and pain, stiffness, and swelling in the left wrist, elbow, and shoulder joints limited his activities to minimal self care. The patient was classified as "Stage 3, active, class 3 ".

Therapy.-The patient was placed on testosterone propionate intramuscularly, two injections per week. After the first injection $(300 \mathrm{mg}$.) pain and swelling in ankles markedly diminished for 24 hours, and after the second injection $(250 \mathrm{mg}$.) the psoriasis was objectively and subjectively improved. During the second week he received two injections of $500 \mathrm{mg}$. testosterone propionate intramuscularly, after the first of which the left wrist was symptom-free for 24 hours, and the left ankle and heel were free from pain for 3 days. After the second injection of $500 \mathrm{mg}$., there was a similar improvement which was maintained during the third week on $500 \mathrm{mg}$. twice weekly. After the 3rd week the sedimentation rate had declined to $14 \mathrm{~mm}$. (uncorrected 21); the patient was walking well, and had only minimal pain and swelling in ankles, wrists, and feet. The psoriasis had entirely disappeared from the trunk and was greatly improved elsewhere, and he was making plans to return to work. From the fourth to the seventh week on $500 \mathrm{mg}$. twice weekly this improvement was maintained (Grade 2 response). The patient was now at work, and had no pain, swelling, or stiffness in the joints, and only some vasomotor symptoms (weakness and sweating). He now found it necessary to shave twice a day, whereas previously once every day or every other day was sufficient. The contrast with his 
condition before treatment (crippled and unable to care for himself, and complaining " that he was dying a slow death ") as compared with the alert, vigorous person who had now returned to his job as salesman after treatment with testosterone propionate was remarkable. During the eighth and final week the dosage was increased to $500 \mathrm{mg}$. three times. The sedimentation rate had now fallen to normal (10 mm., uncorrected 18$)$, and the patient was entirely symptom-free. There had also been a 15-lb. weight gain during the 8 weeks (Grade 1 response). Two weeks after discontinuing the testosterone, there was a return of minimal pain in the wrist and ankles, and the sedimentation rate rose to $20 \mathrm{~mm}$. (uncorrected 22). Six weeks later, the articular pain and swelling had increased in the ankles and wrist $(++)$, and weakness and vasomotor symptoms prevented the patient from working. The sedimentation rate was abnormally elevated $(18 \mathrm{~mm}$., uncorrected 19), and there was also a 12-lb. weight loss since the withdrawal of testosterone.

$450 \mathrm{mg}$. testosterone propionate in aqueous macrocrystalline suspension* was now started. For 10 days after a single injection there was a remission in the articular signs and symptoms and the patient returned to his job. After one week the sedimentation rate had returned to normal ( $7 \mathrm{~mm}$., uncorrected 9) (Grade 1 response). After this single injection of testosterone propionate, the 17 -ketosteroid excretion rose to $38.4 \mathrm{mg}$. $/ 24 \mathrm{hrs}$ on the 1st day, gradually falling to $21.6 \mathrm{mg} . / 24 \mathrm{hrs}$ on the sixth, $12.2 \mathrm{mg} . / 24 \mathrm{hrs}$ on the seventh, and $11.9 \mathrm{mg} . / 24 \mathrm{hrs}$ on the eleventh day, the last value being within the preinjection range. Coinciding with the return of the 17-ketosteroids to pre-injection levels, there was an exacerbation of arthritic signs and symptoms.

\section{Results}

The administration of pregnenolone, acetoxypregnenolone, and testosterone in large doses to five patients in the minimal disease state of rheumatoid arthritis failed to reverse this delicate balance. The erythrocyte sedimentation rate remained abnormally elevated, and the arthritis signs and symptoms were not perceptibly affected. The addition intramuscularly of $25 \mathrm{mg}$. cortisone acetate per 24 hours, was sufficient to reverse the minimal disease state of rheumatoid arthritis in the patients studied, the sedimentation rate falling to normal, and the disease becoming asymptomatic, with complete disappearance of articular inflammation. This reversal occurred within 7 days, yet neither 400 to $500 \mathrm{mg}$. pregnenolone intramuscularly per 24 hours for 21 days, 300 to $500 \mathrm{mg}$. acetoxypregnenolone intramuscularly per 24 hours for 14 days, nor $250 \mathrm{mg}$. of testosteronepropionate intramuscularly per 24 hours for 14 days, was able to produce the anti-rheumatic effect of the $25-\mathrm{mg}$. increment of cortisone. These preliminary studies of pregnenolone, acetoxy-pregnenolone, and testosterone, show that if they have any anti-rheumatic activity at all it is less than 10 per cent. of that of cortisone.

A method has thus been developed for expressing the activity of unknown steroids as a percentage of the anti-rheumatic activity of cortisone. So far, none of the hormones studied by the method of "cortisone comparison ", appeared to have any anti-rheumatic activity at all.

In a separate series of three patients, two underwent dramatic remission while on testosterone therapy, and a third markedly improved, the erythrocyte sedimentation rate becoming normal and signs and symptoms disappearing (Grade 1 improvement). These patients fulfilled the criteria outlined on page 235,

\footnotetext{
* Ciba preparation of testosterone large crystal suspension.
} 
having been observed for 2 to 10 years, during which time there had been no remission and the erythrocyte sedimentation rate had remained abnormally elevated, except for occasional normal values. In all the patients studied with testosterone therapy, the sedimentation rate was lowered independently of the disease activity, and in all the patients who showed no response to testosterone, there was subsequent remission on cortisone therapy, though while in a state of minimal disease activity, they showed no improvement when testosterone was added to the cortisone. It is therefore possible that variants exist in the types of rheumatoid arthritis, some of which respond to certain steroids but not to others.

\section{Summary and Conclusions}

Methods of eliminating significant variables encountered in research in rheumatoid disease are outlined.

A method is described of eliminating one important variable-the severity or degree of activity of the disease. The patient is given the maximum ineffective dose of cortisone (which maintains him with minimal disease activity), and then sufficient cortisone to cause remission is added, so that the exact amount necessary to maintain remission is known.

New untested steroids are administered to these patients with minimal disease activity, and if any anti-rheumatic activity is observed, it can be quantitatively equated with the anti-rheumatic activity of cortisone.

When pregnenolone, acetoxypregnenolone, and testosterone were studied by this method it was found that any anti-rheumatic activity of these three steroids in rheumatoid arthritis was less than 10 per cent. of the activity of cortisone and was not observable clinically. An increment of $25 \mathrm{mg}$. cortisone acetate intramuscularly per 24 hours, in place of the test steroid, caused the disappearance of the signs and symptoms of rheumatoid arthritis and normalized the sedimentation rate within 7 days.

It is suggested that the effect of testosterone in rheumatoid arthritis needs further study. A remission (Grade 1 response) was observed in two patients treated with testosterone under controlled conditions, but no effect (Grade 4) was perceptible in other patients in whom a remission (Grade 1) was afterwards seen on cortisone therapy.

This method of testing steroids in terms of "cortisone activity" by reversal of the "minimum disease state" lends itself to the investigation of the antirheumatic activity of other steroids yet to be tried. This and the other methods set forth may be applied to any field of clinical research, but are especially useful in the study of the rheumatic disease.

Acknowledgements are due to Professor J. S. L. Browne, Director of the University Clinic, for his inspiration and encouragement in this work, and to Dr. L. Johnson for his selection of cases from the Out-Patient Department of the Royal Victoria Hospital, Montreal. The charts presented were prepared by Miss Shirley Ellis. The hormones used in this study were supplied by Dr. B. L. Frank of Ciba Co. Ltd., Montreal, Canada 
(Testosterone Propionate, “ Perandren "), Dr. Edward E. Henderson of Schering Corp., Bloomfield, New Jersey (Pregnenolone, "Pregnenolon ", and Acetoxypregnenolone), and the National Research Council of Canada (Cortisone, "Cortone" Merck, under a grant to Professor J. S. L. Browne).

\section{REFERENCES}

Hench, P. S., Kendall, E. C., Slocumb, C. H., and Polley, H. F. (1949). Proc. Mayo Clin., $24,181$. Liefmann, R. (1950). Acta med. scand., 136, 226.

Short, C. L., and Bauer, W. (1948). New Engl. J. Med., 238, 142.

Venning, E., Johnson, L., and Rose, B. (1951). In "Proceedings of the Second Clinical ACTH Conference", ed. J. R. Mote. Blakiston, Philadelphia.

Steinbrocker, O., Traeger, C. H., and Batterman, R. C. (1949). J. Amer. med. Ass., 140, 659.

\section{Activité Anti-rhumatismale de Plusieurs Stéroìdes}

\section{RÉSUMÉ ET CONCLUSIONS}

L'auteur esquisse les méthodes d'élimination de variables importantes rencontrées dans les recherches sur l'arthrite rhumatismale.

Une méthode, conçue afin d'éliminer la variabilité déterminée par la gravité et par le degré d'activité de l'arthrite rhumatismale, consiste à administrer la dose inefficace maxima de cortisone (maintenant le malade en état d'activité morbide minime). La dose additionnelle de cortisone, nécessaire pour produire le rétablissement du malade, sert d'étalon pour les autres substances capables de produire le même effet.

L'activité anti-rheumatismale de la testostérone, de la pregnénolone, et del'acétoxypregnénolone, étudiée par cette méthode, se montra inférieure à $10 \%$ et ne porta pas sur les signes cliniques. La dose supplémentaire de $25 \mathrm{mg}$. d'acétate de cortisone par voie intramusculaire par 24 heures fit disparaître les signes de l'arthrite rhumatismale et ramena la vitesse de la sédimentation globulaire à la normale en moins de 7 jours.

L'effet de la testostérone dans l'arthrite rhumatismale demande des études ultérieures. Un rétablissement (amélioration du premier degré) fut observé chez deux malades traités par la testostérone dans des conditions contrôlées, mais aucun effet (du quatrième degré) ne fut observé chez d'autres malades chez qui, plus tard, on obtint un rétablissement (du premier degré) avec la cortisone.

Cette méthode d'étalonnage des stéroïdes en fonction d'activité de la cortisone par inversion de "l'état morbide minime" se prête aux recherches sur l'activité anti-rhumatismale des autres stéroïdes pas encore soumises à l'épreuve. Celle-ci, ainsi que d'autres méthodes destinées à contrôler les variables, mentionnées ci-dessus, peuvent s'appliquer à n'importe quelle recherche clinique, mais elles sont particulièrement utiles dans l'étude de l'arthrite rhumatismale.

\section{Actividad Antirreumática de Ciertos Esteroides}

\section{Resumen y CONCLUSIONES}

El autor reseña los métodos de eliminación de variables significativas encontradas en las investigaciones acerca de la artritis reumatoide.

Un método, concebido para eliminar la variabilidad debida a la gravedad y al grado de actividad de la artritis reumatoide, consiste en administrar la dosis ineficaz maxima de cortisona (manteniendo el enfermo en el estado de actividad mórbida mínima). La dosis adicional de cortisona necesaria para producir el restablecimiento del enfermo sirve de patrón para las otras substancias experimentales, destinadas a producir el mismo efecto.

La actividad antirreumática de la testosterona, de la pregnenolona, y de l'acetoxypregnenolona, estudiada por este método, se mostro inferior à $10 \%$ y sin influencia sobre los signos clínicos. La dosis suplementaria de $25 \mathrm{mg}$. de acetato de cortisona por vía intramuscular administrada por 24 horas hizo desaparecer los signos de la artritis reumatoide y normalizó la sedimentación globular en menos de 7 dias.

El efecto de la testosterona sobre la artritis reumatoide demanda estudios ulteriores. El restablecimiento (mejoría de primer grado) fué observado en el caso de dos enfermos tratados con testosterona en condiciones controladas, pero ningún efecto palpable (de cuarto grado) se pudo observar en otros enfermos en los cuales se obtuvo posteriormente restablecimiento (de primer grado) con cortisona.

Este método de valuación de los esteroides en función de la actividad de la cortisona, por reversión del "estado mórbido mínimo" se presta para investigar la actividad antirreumática de otros esteroides aún no comprobados. Este, así como otros métodos, mencionados arriba, concebidos para controlar los variables, se pueden aplicar a cualquier otra investigación clínica, pero son particularmente útiles en el estudio de la artritis reumatoide. 